\title{
Employees' Information System Usage Behavior Evolution Based on Social Network Analysis Perspective
}

\author{
Min Qin ${ }^{1, a}$, Jingjing Guan ${ }^{1, b}$ \\ ${ }^{1}$ Research Center of Management Science \& Engineering, School of Software, Jiangxi Normal \\ University, Nanchang, 330022, China \\ aemail: helenqin126@163.com, bemail:guanjingjing3426@163.com
}

\begin{abstract}
Keywords: Information Systems; Behavior Evolution; Habitual Usage Behavior; Innovative Usage Behavior; Social Network Analysis
\end{abstract}

\begin{abstract}
Prior research has studied individual-level information system post-adoption usage, primarily regarding cognitive factors as predictors of individual usage behavior. We suggest that employees should be embedded in the social network of the organizational unit, and their interactions with coworkers can promote the usage behavior evolution from habitual usage behavior to innovative usage behavior over time. In this paper, we propose a research model of individual IS usage behavior evolution. Then we take the longitudinal period of 3 years and choose two typical periods to collect the valid data. Through both in-depth interviews and social network analysis approach, empirical results show that there is a close relationship between changing social networks and employees' information system usage behavior evolution. In the Low network density and centrality are positively associated with employees' habitual usage and high network density and centrality are positively associated with employees’ innovative usage.
\end{abstract}

\section{Introduction}

One of the most welcome developments in Information Systems scholarship has been the growing interest in post-adoptive information system (IT/IS) usage [1]. There are a variety of labels about different individual-level post-adoptive IS usage behavior, such as IS continuance, habitual usage, deep structure usage, mindful usage, innovative (exploitative \& explorative) usage [2], and so on. As a whole, the IS literature on post-adoptive usage separately emphasizes the determinants of above different usage behaviors, primarily taking the horizontal research methods. The basic premise is that individual IS usage behavior shows changeless and static.

However, as for an enterprise, due to the variability from internal requirements and external environment, employees' IS usage behavior should not always be expected to the single and fixed behavior model. Intrigued by this argument, through reading the most commonly cited literature, we believe that it is important for the field to explain the individual IS usage behavior evolution process and mechanism. The plan of this essay is as follows. We first start with a brief literature review about IS habitual usage and exploitative usage behavior. It also reviews main streams of network-based analyses in information system research. Then, we suggest a research model of individual IS usage behavior evolution and some hypotheses. Next, it describes an empirical research method. Finally, the data analyses and research results are reported and discussed.

\section{Theoretical Background}

Habitual usage behavior is conceptualized as repeated behavioral sequences automatically triggered by environmental cues In some studies, individual habit moderates the impact of intentions on the guidance of IS use. In others, individual habit directly influences future intentions to use IS [3]. Theoretically, in stable contexts and over time, continuing IS usage becomes habitual, which means that well-learning action sequences may be activated by environmental cues and then repeated without conscious intention.

Although much attention is paid to the habitual usage of IS, post-adoptive behavior is defined as 
the myriad feature adoption decisions, feature use behaviors, and feature extension behaviors made by an individual user after an IT application has been installed.

The conception of IS innovative usage can be understood to contain the following meanings: (1) users exploit and extend the more functions/features of systems to perform business tasks; (2)users explore or yield novel ways to use organizational systems, and new ways goes beyond the simply using of IT in a prescribed way. Theoretically, both individual or internal factors (knowledge, behavioral intention, ability,..) and organizational or external factors (support, climate, facilitating conditions,.. ) are more likely to influence an employee’s IS innovative usage behaviors.

Generally speaking, innovative usage behavior can be regarded as the most important and the highest-level usage behavior after initial adoption [4].

The social network perspective draws on the patterns of interactions and exchanges within social units in which an actor is embedded to explain outcomes experienced by the actor. According to this perspective, an employee's position in a social network is associated with the access to network information and resources. The structure of social interactions enhances or constrains to valued resources and valued information. Work-related resources, such as task advices and strategic information, are accessible through social networks. People usually learn new idea through associating those ideas with existing knowledge. It is easier for knowledge to transfer among people with similar training, background, and job characteristics. This implies that employees in an enterprise unit are more likely to be fruitfully engaged in knowledge sharing that shapes their continued or innovative usage of systems.

In the new digital economy, inter-organizational collaboration and innovation are becoming more central to organizational effectiveness, and people weave and draw upon whilst accomplishing their work. Recent years, IS scholars have started to pay more attention on social network approaches, and proposed to understand the uses of social network analysis related to IS use within and outside an organization. Some researchers have make progress in individual-level IS usage with social network analysis perspective. Following to the suggestions and research directions from these literatures, we devote the relationship between long-term individual IS usage behavior evolution and changing social networks.

\section{Research Methodology}

Based on above literature analyses, combined with our field investigate on a large-scale motor manufacturing enterprise and face-to-face survey on some key systems users, we propose a conceptual model of employees' IS usage behavior evolution, which mainly focus on the evolution path from habitual usage to innovative usage as Fig.1.

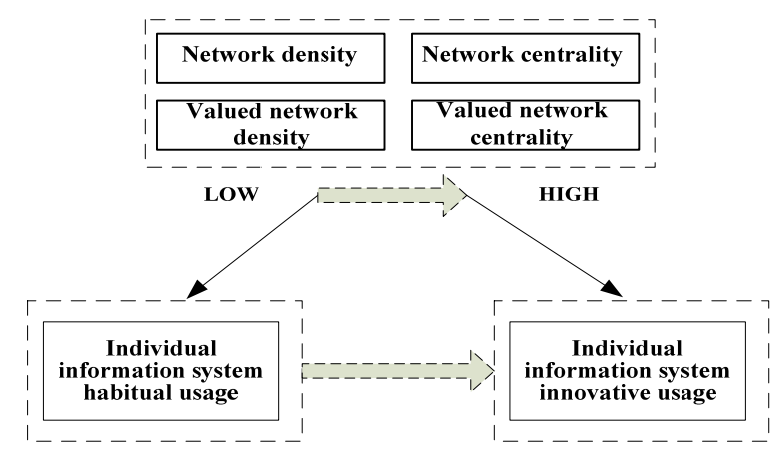

Figure1. The conceptual model of IS usage behavior evolution

Network density describes the connectedness of a network and is defined as the actual number of ties in a network as a proportion of the maximum possible number of ties. In this research, we adopt an egocentric conceptualization of density referring to an individual's interaction with others in an organizational unit to obtain help, which means each employee has a score that marks how much help he or she gets from colleagues. We term valued network density.

Within an enterprise, an employee's perceptions of system-related density and centrality can be anchored to general friendship and advice networks. When system users are taking the automatic or 
repeated /habitual usage behavior, they usually need not get system-related help from the others and may show weak connection with their coworkers. Effective and innovative information systems usage requires co-adaption of the information system and the organization. Resources accessed through the social network at the workplace can help employees learn features unique to the system, gain the skills needed to effectively use the system, and deal with the adjusted work processes. The support received by employees through their social network is more likely to be greater if the network consists of people who occupy social positions that control resources, such as information, system-related knowledge and so on [5]. Valued network density takes into account the focal actor's social ties weighted by the control of knowledge, information, and other resources that support and direct how to use information systems in an effective way. Therefore, we have the following hypotheses: H1(a): low valued network density is positively associated with individual habitual usage behavior. H1(b): High network density is positively associated with individual innovative usage behavior. H2(a): low valued network density is positively associated with individual habitual usage behavior. H2(b): High valued network density is positively associated with individual innovative usage behavior.

Network centrality is defined as the extent of an individual's involvement in assistance exchanges with coworkers. Based on the existing research, we focus on centrality based on the number of ties an individual has with others in an organizational unit to provide help, which we term valued network centrality, refers to peer's perceptions of the level of system-related resources controlled by a focal employee. A relative central position in help network is expected to augment an employee's access to knowledge, thus affecting his ability to recognize opportunities. Centrally positioned employees tend to be more active in organizational innovation and can be expected to be early and more proficient users of information systems, thus leading to greater innovative use. Valued network centrality reflects the perception of an employee's peers about the extent to which the controls resources that can contribute to the effective usage of systems [6]. Therefore, we have the following hypotheses: H3(a): low network centrality is positively associated with individual habitual usage behavior. H3(b): high network centrality is positively associated with individual innovative usage behavior. H4(a): low valued network centrality is positively associated with individual habitual usage behavior. H4(b): high valued network centrality is positively associated with individual innovative usage behavior.

In order to examine our conceptual model, we tracked a large-scale motor manufacturing in Jiangxi Province for investigating internal employees' information systems usage and collecting related data. In the past 3 years, we took in-depth interviews with over 20 employees form IT department and marketing department in this company. At the same time, we choose two periods (2010.6-2010.9 and 2012.9-2012.12) to collect the valid data, and respectively got 98 employees' and 102 employees' valid questionnaires. This motor manufacturing enterprise had successfully implemented the new ERP system to replace the old fragmented systems in 2009. This system helped streamline the process of managing key business modules, including sales distribution, material management, production planning et al. After the new system was adopted, the important business processes and job tasks were required to carry out through integrated ERP platform.

Due to the complexity and various features of the adopted ERP system, system usage training courses were provided by the software supplier and IT department of the enterprise to guarantee the personnel in the focal business unit to use system. Based on our field survey and in-depth interviews, we choose two periods as the typical behavior stage; that is, taking Jun. 2010 to Sept. 2010 as the habitual usage stage and Sept. 2012 to Dec.2012 as the innovative usage stage. We collected social network data using a roster-based socio-metric approach. This approach employs a fixed contact roster and asks respondents to describe their relationship with every individual on the roster. These data were used to compute the four social network constructs discussed. We used the get-help network to create the network density measures because these measures reflect the employee's ability to effectively use systems, and the give-help network to create the network centrality measures because the centrality measures reflect the employee's ability to influence the deployment of systems. 
The social network constructs were measured as following: Network density was computed for each employee, considering the out-neighborhood, and in this study it means get-help network. The density is given by number of dichotomized ties divided by the number of possible pairs. Valued network density was measured for each employee by weighting tie-strength by the average assessment of controlled resources. Network centrality was measured for every vertex in the give-help network. Valued network centrality was computed based on an assessment derived from respondents' evaluations of resources controlled by other employees. Two key predictors of social networks are measured: Get-help $p_{\mathrm{ij}}$ Assessment of frequency of contacts made to get system-related help from employee $\mathrm{j}$. Give-help $\mathrm{ij}_{\mathrm{ij}}$ Assessment of frequency of contacts made by employee $\mathrm{j}$ seeking system-related help.

The unit of analysis in this study is an individual employee, that is, a mandatory user of enterprise's systems. The sampling frame consisted of all employees of some key business units in this enterprise. The members were knowledge workers whose use of the systems was mandatory. Membership in these business units formed an appropriate boundary for our study because the members interacted in the context of the interdependent processes and share symbol system. Two constructs of habitual usage behavior and innovative usage behavior are respectively measured using five items and six items based on the prior literature.

\section{Result Analysis}

We illustrate the social network analysis conducted on the full sample with the help of a small subsample of the socio-metric data. We use UCINET6.212 to analyze the data for 14 employees obtained through our two surveys. Fig. 2and 3 respectively provide the visual depiction of the patterns of help interactions in this network of 14 employees. We used partial least squares (PLS) to test the research model listed in Tab.1. The structural models are tested to understand the explanatory power of the social network constructs. The path coefficients of hypotheses show significant. As a result, all hypotheses are supported.

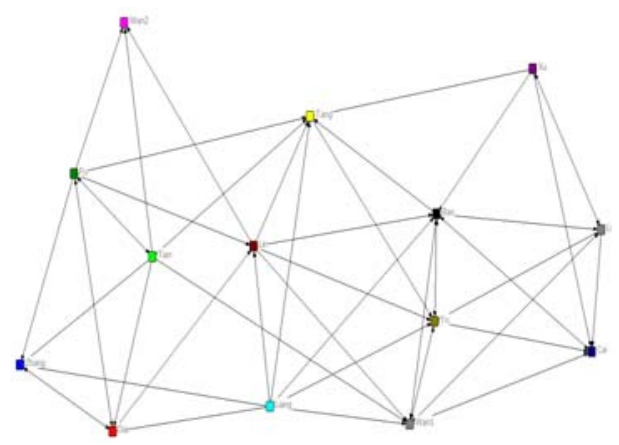

Figure2. Average get-help \& give-help ties

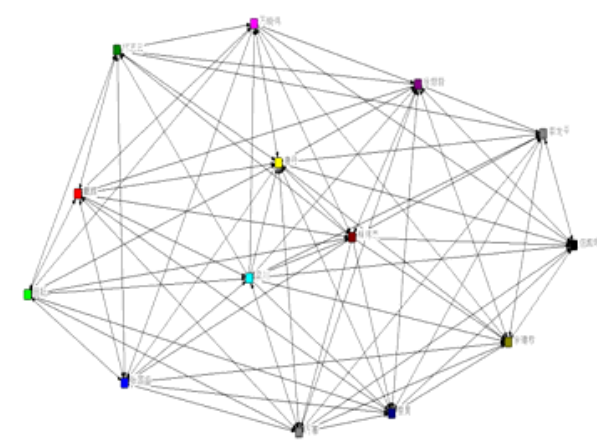

Figure3. Average get-help \& give-help ties

\begin{tabular}{|c|c|c|c|c|}
\hline & Mean & Std Dev. & $\begin{array}{c}\text { habitual } \\
\text { usage }\end{array}$ & $\begin{array}{c}\text { innovative } \\
\text { usage }\end{array}$ \\
\hline $\mathrm{ND}(1)$ & 2.89 & 2.31 & $0.29^{* *}$ & \\
\hline $\mathrm{VND}(1)$ & 1.93 & 2.59 & $0.30^{* *}$ & \\
\hline $\mathrm{NC}(1)$ & 2.87 & 1.25 & $0.28^{* *}$ & \\
\hline $\mathrm{VNC}(1)$ & 1.82 & 1.78 & $0.29^{* *}$ & \\
\hline $\mathrm{ND}(2)$ & 3.89 & 2.01 & & $0.35^{* *}$ \\
\hline $\mathrm{VND}(2)$ & 2.93 & 1.90 & & $0.31^{* *}$ \\
\hline $\mathrm{NC}(2)$ & 4.37 & 2.25 & & $0.29^{* *}$ \\
\hline $\mathrm{VNC}(2)$ & 3.02 & 2.11 & & $0.30^{* *}$ \\
\hline
\end{tabular}

Some conclusions can be gotten from above analysis results: (1) low valued network density and network centrality are associated with IS habitual usage; (2) high valued network density and network centrality are associated with IS innovative habitual usage; (3) there is a close relationship between employees' IS usage behavior evolution with the changing social network predictors. 


\section{Acknowledgement}

In this paper, the research was sponsored by following Foundation: (1) National Science Foundation of China (71262023) ;(2)Humanities \& Social Science Youth Foundation of Ministry of Education (10YJC630194); (3) Soft Science Research Foundation of Jiangxi Province (20112BAA10032) ; (4)Humanities \& Social Science Foundation of Jiangxi Province (GL1143) ; (5) Science \& Technology Support Project of Jiangxi Province (2009ZDG04700) ; 6Doctoral Foundation of Jiangxi Normal University.

\section{References}

[1] J. Jasperson, P. E. Carter, and R. W. Zmud. A comprehensive conceptualization of post-adoptive behaviors associated with information technology enabled work systems[J] MIS Quarterly, 2005.29, 525-557.

[2] A. Burton-Jones, and D. Straub. Reconceptualizing system usage: an approach and empirical test [J]. Information Systems Research, 2006(17), 228-246.

[3] S. S. Kim, and N. K. Malhotra. A longitudinal model of continued IS use : an integrative view of four mechanisms underlying postadoption phoneomena [J].Management Science, 2005(151).741-755.

[4] H. L. Adams. Mindful Use as a Link Between Social Capital and Organizational Learning: An Empirical Test of the Antecedents and Consequences of Two New Constructs [D]. University of Maryland, 2006

[5] Y. Yoo. Computing in everyday life: a call for research on experiential computing [J].MIS Quarterly. 2010. 34 (2). 213-231.

[6] J. Putzke, K. Fischbach, D. Schoder, and P. A. Gloor. The evolution of interaction networks in massively multiplayer online games [J].Journal of the Association for Innformation Systems, 2010(11).69-94. 